\title{
Rural-urban differences in hunting and birdwatching attitudes and participation intent
}

\author{
Emily J. Wilkins (10), Nicholas W. Cole $\mathbb{0}^{\mathrm{a}}$, Holly M. Miller ${ }^{\mathrm{b}}$, Rudy M. Schuster ${ }^{\mathrm{b}}$, \\ Ashley A. Dayer $\mathbb{D}^{c}$, Jennifer N. Duberstein ${ }^{d}$, David C. Fulton ${ }^{\mathrm{e}}$, Howard. W. Harshaw (1) \\ and Andrew H. Raedeke (10) ${ }^{\mathrm{g}}$
}

${ }^{a}$ Work done under contract to U.S. Geological Survey, Fort Collins, CO, USA; bU.S. Geological Survey, Fort Collins Science Center, Fort Collins, CO, USA; 'Virginia Tech, Department of Fish \& Wildlife Conservation, Blacksburg, VA, USA; 'Sonoran Joint Venture, U.S. Fish and Wildlife Service, Tucson, AZ, USA; eU.S. Geological Survey, Minnesota Cooperative Fish and Wildlife Research Unit, University of Minnesota, Saint Paul, MN, USA; ${ }^{f}$ Faculty of Kinesiology, Sport, and Recreation, University of Alberta, Edmonton, AB, Canada; ${ }^{9}$ Missouri Department of Conservation, Columbia, MO, USA

\begin{abstract}
Outdoor recreation facilitates important connections to nature and wildlife, but it is perceived differently across population segments. As such, we expected that socio-demographic characteristics of individuals would influence intention to participate in outdoor recreation. We solicited 5,000 U.S. residents ( $n=1,030,23 \%$ response rate) to describe their perceptions of hunting and birdwatching. The influence of current and childhood community size (i.e., urban-rural) was examined as a potentially important predictor of intention to participate in hunting and birdwatching, along with attitudes, norms, and perceived behavioral control (PBC). Hunting intentions, attitudes, norms, and PBC were more positive when respondents maintained a residence in rural areas. Alternatively, birdwatching attitudes, norms, and PBC did not differ with current or childhood community size. Programs aimed at increasing participation in outdoor recreation should carefully consider the importance of the urban-rural residence gradient in the context of their objectives, especially for recruiting urban hunters.
\end{abstract}

\section{KEYWORDS}

Community size; environmental attitudes; outdoor recreation; Theory of Planned Behavior; urban-rural

\section{Introduction}

Spending time in nature contributes to mental and physical health in both children and adults, as well as increases positive emotions and attentional capacity (Mayer, Frantz, Bruehlman-Senecal, \& Dolliver, 2009; Pretty, 2004). Outdoor recreation provides important outlets for people across a wide variety of socio-economic backgrounds to connect with nature (Larson, Stedman, Cooper, \& Decker, 2015; Lovelock, Walters, Jellum, \& Thompson-Carr, 2016). Many conservation-based organizations have recognized that strengthening connections to nature through increasing participation in outdoor recreation is critical to fostering long-term support for conservation initiatives among people in both urban and rural environments (Cooper, Larson, Dayer, Stedman, \& Decker, 2015; Lichter \& Brown, 2011; Teel \& Manfredo, 2010). In this paper, we compare and contrast the role of socio-demographic background in its relationship to

CONTACT Emily J.Wilkins emily.wilkins@aggiemail.usu.edu E Utah State University, 5215 Old Main Hill, Logan, UT 84322, USA 
intent to participate in two outdoor recreation activities that rely on similar access and resources, but diverge in motivation and behavior. These activities are birdwatching and hunting.

Historically, differing socio-demographic backgrounds have been represented via the urban-rural residence gradient where ruralness was thought to be representative of fundamentally different perceptions and values than urban counterparts (Lichter \& Brown, 2011). However, the urban-rural gradient has become narrower with more overlap between urban and rural communities due to increasing urban sprawl, social connectedness, and exchange of migrants (Woods, 2009). People with different socio-demographic backgrounds may experience different functional limitations to participating in outdoor recreation, but given the narrowing of the gradient, this may not translate to different behavior when it comes to participating in outdoor recreation (Weber, Jensen, Miller, Mosley, \& Fisher, 2005). As such, it is useful to understand how position on the urban-rural residence gradient (both currently and as a child) relates to participation in hunting and birdwatching (McFarlane \& Boxall, 1996; Robison \& Ridenour, 2012; Stedman \& Heberlein, 2001).

\section{Hunting and Birdwatching Participation}

In $2011,6 \%$ of the U.S. population 16 years or older participated in hunting, which declined to $4 \%$ by 2016 (U.S. Fish and Wildlife Service \& U.S. Census Bureau, 2014, 2018). By 2060, the percentage of the population who hunts is expected to decline by $22-31 \%$ from 2010 levels (Cordell, 2012). Many other countries across Europe and North America are also experiencing declines in hunting participation (Heberlein, 2008). In 2016, 18\% of Americans participated in birdwatching, with $36 \%$ of birdwatchers viewing birds away from home (U.S. Fish and Wildlife Service \& U.S. Census Bureau, 2018). The national participation rate declined slightly from 19\% in 2011 to 18\% in 2016 (U.S. Fish and Wildlife Service \& U.S. Census Bureau, 2014, 2018). Young adults (ages 18-44) represent $46 \%$ of the adult population in the U.S., but this group comprises only $39 \%$ of all hunters and $33 \%$ of around-the-home wildlife viewers (U.S. Fish and Wildlife Service \& U.S. Census Bureau, 2018), indicating that young adults may be less engaged in wildlife-related recreation than their older counterparts.

For any socio-demographic segment, lower than expected engagement in wildlife-related recreation is concerning, as research suggests that engaged individuals are more likely to express positive conservation behaviors relative to people who do not participate in wildliferelated recreation (Cooper et al., 2015; Glowinski \& Moore, 2014). Increased participation and involvement in hunting has been tied to the age of introduction to the activity and level of socialization among individuals' social networks (Larson, Stedman, Decker, Siemer, \& Baumer, 2014; O'Leary, Behrens-Tepper, Mcguire, \& Vio, 1987; Quartuch et al., 2017; Stedman \& Heberlein, 2001). As recreational hunting is more popular and prevalent among rural residents in North America, it is to be expected that increasing urbanization may result in a decreased likelihood of participation in recreational hunting (Larson et al., 2014). For birdwatchers, this relationship seems to be regionally specific where in some cases more participants reside in urban areas (McFarlane \& Boxall, 1996), but in others, those residing in small cities and rural areas maintain higher participation rates (La Rouche, 2003). As such, drawing comparisons between participation behavior in birdwatching and hunting across the urban-rural residence gradient is likely important to ongoing efforts to increase participation and encourage positive conservation behavior. 


\section{Rural-Urban Differences}

In 1950, 64\% of Americans lived in urban areas (defined as communities with more than 2,500 people), and by 2010 that increased to $81 \%$ (U.S. Census Bureau, 1993, 2015). Previous studies have shown that people living in urban areas tend to express different opinions, attitudes, and behaviors related to a wide range of topics compared to people in rural areas (e.g., Berenguer, Corraliza, \& Martín, 2005; Coleman, Ganong, Clark, \& Madsen, 1989; Howell \& McFeeters, 2008).

A survey by the USDA Forest Service found that there was a significant difference between urban and rural residents' hunting and fishing participation; $43 \%$ of rural residents reporting hunting or fishing participation, compared to 32\% of urban residents (Cordell, 2012). However, there were no significant differences between the number of people who participated in wildlife viewing or photographing nature (Cordell, 2012). The U.S. Fish and Wildlife Service and U.S. Census Bureau (2014) reported that hunting participation was highest in areas with populations of fewer than 50,000 people (18\%) and lowest in urban areas of 1 million or more residents (3\%). Wildlife viewing was highest in areas under 50,000 people (38\%) and lowest in large urban areas (25\%). These results suggest that current community size may be related to wildlife-related recreation participation. Although these studies examined the effect of current community size on wildlife-related behaviors, they did not investigate the effect of urban or rural childhood residency on participation in wildlife-related outdoor activities, or differences in attitudes toward these activities. One previous study investigated the differences in hunting attitudes between urbanites who grew up in rural areas and those who did not (Heberlein \& Ericsson, 2005). The authors found multigenerational urbanites in Sweden had more negative attitudes toward hunting than urbanites who grew up in rural areas. This indicates both childhood and current community size may influence attitudes and behavioral intentions related to wildlife-associated recreation.

Broadly, research has shown that childhood and current community size can be related to a variety of environmental behaviors (Berenguer et al., 2005; Cooper et al., 2015; Walker \& Ryan, 2008). Previous research has shown some behaviors that support the environment are more common in urban areas, such as recycling and using public transit; other behaviors are more common in rural areas, such as land stewardship (Kollmuss \& Agyeman, 2002; Larson et al., 2015). This is likely due to access to these opportunities and programs (e.g., recycling or public transit) rather than environmental attitudes of the individuals undertaking the actions (Huddart-Kennedy, Beckley, McFarlane, \& Nadeau, 2009). At the same time, differences in environmental behaviors between urban and rural residents have been diminishing, partially due to more people moving to places as adults that are different from where they grew up (Jones, Fly, Talley, \& Cordell, 2003). However, Huddart-Kennedy et al. (2009) found the community in which a person grew up did not affect environmental concern as much as current place of residence. For example, people socialized in a rural place, but who moved to an urban area, were more similar to those who grew up and currently live in urban areas than people who grew up and currently live in rural areas (Huddart-Kennedy et al., 2009). However, these studies investigated environmental behaviors and their relationship to urban or rural residence in general and did not focus on specific wildlife-related recreation, which generally has a stronger relationship with rural communities (Quartuch et al., 2017).

Although some research has addressed urban-rural differences in general environmental attitudes (Jones, Fly, \& Cordell, 1999; Lowe \& Pinhey, 1982), only a few studies have 
specifically addressed urban-rural differences related to wildlife-related attitudes and behaviors. A study of attitudes toward wildlife management found that people raised in rural or small town areas had a higher likelihood of supporting predator control compared to people raised in urban settings, but current residence was an even stronger predictor than where someone was raised (Reiter, Brunson, \& Schmidt, 1999). Additionally, rural residents were less likely than urban residents to oppose the use of hunting and baiting to manage black bear and cougar populations, possibly because they have more direct experience with wildlife (Teel, Krannich, \& Schmidt, 2002). Zinn, Manfredo, and Barro (2002) found that the proportion of a person's upbringing that took place in rural areas was a stronger predictor of wildlife value orientations than the proportion of adulthood spent in rural areas. Increased urbanization has also been linked to a shift from domination to mutualism wildlife value orientations and subsequent wildlife-related attitudes and behaviors (Manfredo, Teel, \& Henry, 2009). Collectively, these studies suggest that the level of urbanization of communities in which people grew up and currently reside are associated with different wildlife-related attitudes, participation, and value orientations. However, these studies have not investigated the effects of community urbanization-level on wildlife-related recreation attitudes and participation.

\section{Conceptual Background and Objectives}

Researchers have used the Theory of Planned Behavior (TPB; Ajzen, 1991) extensively to predict and model different aspects of human behavior in wildlife-related recreation contexts (Miller, 2017). The TPB states that behavioral intention results from attitudes, subjective norms, and perceived behavioral control (PBC). Behavioral intention is thought to be the proximate cause of actual behavior (Ajzen \& Driver, 1991). Attitudes toward a behavior are believed to be a product of behavioral beliefs, or the perceived outcomes of behavior, and the individual's evaluation of that behavior's outcome. Normative beliefs, or the perceived expectation of others, along with motivations to comply, form subjective norms. Finally, control beliefs, which influence how people judge the factors that may enable or prevent them from participating in a behavior, give rise to PBC (Ajzen \& Driver, 1991). These variables compose the assumed base model that determines behavioral intention, but other factors that may also jointly influence behavior, such as demographic characteristics and values, are considered to be background factors. Background factors are usually assumed to be mediated by attitudes, norms, and PBC, but this is not always true and is dependent on background factor(s) and the outcome variable(s) of interest (Fishbein \& Ajzen, 2010). Depending on the context, the base TPB model may be inadequate and additional background factors may need to be included to account for more of the variance in behavior after attitudes, norms, and PBC (Fishbein \& Ajzen, 2010). Researchers agree there is a need to investigate the possibility of adding other predictor variables to better understand behavioral intentions (Fishbein \& Ajzen, 2010; Miller, 2017).

Researchers have previously used the TPB to predict wildlife-related behavior, including hunting intentions and behavior, and assessed the efficacy of related background factors with varying degrees of success (Hrubes, Ajzen, \& Daigle, 2001; Rossi \& Armstrong, 1999; Shrestha \& Burns, 2016; Shrestha, Burns, Pierskalla, \& Selin, 2012). For example, Rossi and Armstrong (1999) found that attitudes, norms, and PBC explained 38\% of the variation in intent to participate in hunting, and Hrubes et al. (2001) found these concepts explained $93 \%$ of the variation in hunting intention. Shrestha et al. (2012) found that concepts in the TPB could 
predict $78 \%$ of the variance explaining deer hunting behavior. Overall, results suggest that the TPB has some utility for predicting hunting intention and behavior. However, none of these studies investigated the impact of current or childhood community urbanization, and whether they were fully mediated by the TPB elements. Although some studies have used the TPB framework to explain birdwatching intent (e.g., Lessard, 2017), the research is more limited.

In this study, we sought to answer two questions associated with people's intentions to participate in hunting and birdwatching: (a) do people who currently live or grew up in urban or rural areas express differences in attitudes, norms, and $\mathrm{PBC}$ associated with hunting and birdwatching, and (b) does adding the urban-rural character of current and/ or childhood community improve the capacity for the TPB model to explain the variation in people's intent to participate in hunting and birdwatching?

\section{Methods}

\section{Data Collection}

We collected data between January and March 2017 using a mail survey. We sent questionnaires to 5,000 randomly selected adults (18 years and older) from a sample purchased from Survey Sampling International (now known as Dynata) to reflect U.S. demographics and in proportion to the population of each state (Any use of trade, firm, or product names is for descriptive purposes only and does not imply endorsement by the U.S. Government). We used a modified Tailored Design Method and mailed one reminder postcard and a replacement questionnaire to those who did not initially respond (Dillman, Smyth, \& Christian, 2014). We sent those who did not respond to the second questionnaire a half-page non-response questionnaire that asked seven questions; this allowed for a comparison of respondents' and non-respondents' participation in recreation activities. All data are publicly available (Wilkins, Miller, \& Schuster, 2017).

\section{Survey Instrument}

We conducted this research within a broader effort to fulfill the requirements of the 2018 update of the North American Waterfowl Management Plan. We developed a mail questionnaire that had four main sections: (a) nature activities, (b) sources of information about conservation issues, (c) opinions about wetlands, and (d) socio-demographic characteristics. Hereafter, we only refer to portions of the questionnaire that were included in this assessment, but the full instrument is publicly available (Wilkins \& Miller, 2018).

To determine whether respondents' current place of residence and the place where they grew up was urban or rural, we asked: "which of these categories best describes were you live now and which of these categories best describes where you lived during most of the time you were growing up (that is, until age 16)?" We presented five options: rural area $(<2,500$ people), small town $(2,500-10,000$ people), small city (10,000-50,000 people), medium urban area (50,000-500,000 people), and large urban area $(500,000+$ people $)$. To determine past activity participation and future intent, the questionnaire listed 10 naturerelated activities, including hunting and birdwatching. We asked respondents to indicate if they had participated in each activity in the last 12 months (yes or no) and how likely they were to participate in the next 12 months, with three options: not at all likely, somewhat likely, or very likely. 
Other survey instruments that used the TPB informed the wording of our questions about attitudes, norms, and PBC (Daigle, Hrubes, \& Ajzen, 2002; Shrestha et al., 2012). Two questions for each activity measured attitudes toward hunting and birdwatching: we asked respondents to rate whether those activities were unpleasant or pleasant, and boring or interesting (on a five-point scale, with three representing neither). Therefore, attitudes represent respondents' perspectives toward hunting and birdwatching, not toward others participating in those activities. We also asked one question to evaluate subjective norms for each activity, and one question to evaluate PBC. To assess norms and PBC, we presented 5-point interval agreement scales to rate whether people important to them would support them hunting or birdwatching (norms), and if they could easily go hunting or birdwatching in the next 12 months if they so desired (PBC).

\section{Data Analysis}

For initial analysis, we collapsed the urban-level community measurement from five categories to three categories to maintain adequate group sizes while exploring differences between respondents from different childhood and current communities. Therefore, we considered 50,000 + urban, 2,500-50,000 medium, and <2,500 rural, as it is consistent with the U.S. Census Bureau categorization (U.S. Census Bureau, 2015). We split respondents into six categories based on their perceived community sizes (Table 1). These categories are different combinations of perceived current and childhood community size. We used these categories as a way to test differences between groups, while also considering both the size of the childhood community one grew up in as well as the size of their current community. For the purposes of this study, a person's perception of where they live(d) is more relevant than the U.S. Census classification of where they live(d), as it may relate to their beliefs about hunting and birdwatching.

This analysis excluded those raised in a medium urban area, but then moved to a rural area because this group was too small for comparative purposes $(n=33)$. To answer the first research question and determine if there were differences between the six residence groups in hunting and birdwatching intentions, attitudes, norms, and PBC, we calculated chi-square tests of independence with Cramer's $V$ effect sizes. We used an alpha value of .05 to interpret all tests.

We conducted another analysis to answer the second research question: do current and/or childhood residence increase the ability of attitudes, norms, and PBC to predict behavioral intention? To investigate this question, we used ordinal logistic regression to test four models. One model was just the TPB predictors of intention (attitudes, norms, PBC). Model two added current residence, model three added childhood residence, and model four added both current and childhood residence. Fishbein and Ajzen (2010)

Table 1. Categorization and sample sizes of respondents based on current and childhood community size.

\begin{tabular}{lllr}
\hline Label & Size of childhood community & Size of current community & $n$ \\
\hline$U-U$ & Urban & Urban & 301 \\
$M-M$ & Medium & Medium & 219 \\
$R-R$ & Rural & Rural & 82 \\
$U-\downarrow$ & Urban & Medium or Rural & 181 \\
$R-\uparrow$ & Rural & Medium or Urban & 183 \\
$M-U$ & Medium & Urban & 116 \\
\hline
\end{tabular}


considered residence to be a background factor in the TPB, and they suggested testing to see if a background factor is mediated by attitudes, norms, and PBC by adding the background factor as an additional predictor. We tested all four models for both hunting and birdwatching intention to investigate whether the influence of residence size differed between hunting and birdwatching. We measured norms and PBC on their own 5-point scales as discussed above; we measured attitudes as the mean of the two 5-point scales. In this analysis, we used the 5-category response for residence size, with 1 being large urban (population $>500,000$ ) and 5 representing rural (population $<2,500$ ). We used multiple fit indices to assess model fit.

\section{Results}

\section{Profile of Respondents}

Of the 5,000 questionnaires we sent, we received 1,030 completed questionnaires and 595 were undeliverable, which resulted in a response rate of $23 \%$. Of those who did not complete the initial questionnaire, 275 returned the non-response questionnaire. By comparing respondents with non-respondents, there appeared to be some response bias in who chose to complete the questionnaire. People who responded to the full questionnaire had higher rates of birdwatching ( $61 \%$ of the sample compared to $39 \%$ of the nonresponse sample) and hunting (17\% of the sample compared to $14 \%$ of the nonresponse sample) in the last 12 months. The sample of respondents also tended to be older, more educated, less racially and ethnically diverse, and had a higher proportion of males than the general U.S. population as reported by census data (Table 2). Overall, the Midwest was slightly overrepresented, and the South was slightly underrepresented. Given these differences between the sample and both the nonresponse check and the census, results reported here are limited to just the sample and scope of inference cannot be extended to represent the broader population.

\section{Participation, Attitudes, Norms, and PBC by Residence}

Respondents raised in urban settings who currently live in an urban setting (U-U) expressed the lowest intention to participate in hunting, whereas R-R (raised rural, currently rural) had the highest intention to hunt, and $\mathrm{M}-\mathrm{M}$ (raised medium, currently medium) were in the middle (Table 3 ). Those currently in different sized communities from where they grew up had hunting intention rates closest to the M-M respondents. Those who grew up in rural settings and moved to larger communities were more likely to report that they were very likely to hunt than those who grew up urban and moved to a smaller community. However, the effect size of these differences was relatively small (Cohen, 1988). There were also significant differences in birdwatching intent by residence, although the effect size was also small. U-U were the least likely to intend to birdwatch, whereas U- $\downarrow$ (raised urban, currently medium or rural) had the highest proportion report that they were very likely to birdwatch.

There were significant differences among attitudes, norms, and PBC toward hunting based on current and childhood community sizes (Figure 1). R-R respondents had the most positive views of hunting, were most likely to believe that others would support them hunting, and believed that they could easily go hunting. Those who were U-U had the 
Table 2. Demographic characteristics from the survey sample compared to the U.S. census bureau (2015 estimates). Numbers expressed in percentages; $n=1,030$ for the sample.

\begin{tabular}{lcc}
\hline Category & Sample (\%) & U.S. Census (\%) \\
\hline Census region & 20 & 18 \\
$\quad$ Northeast & 28 & 21 \\
Midwest & 31 & 38 \\
South & 22 & 24 \\
$\quad$ West & & \\
Gender & 65 & 49 \\
$\quad$ Male & 35 & 51 \\
Female & & \\
Age & 21 & 48 \\
18-44 (\% of adults) & 46 & 35 \\
45-65 (\% of adults) & 33 & 17 \\
$\quad 65+(\%$ of adults) & & \\
Education & 17 & 41 \\
$\quad$ High school degree or less & 30 & 26 \\
$\quad$ Some college or Associates & 27 & 21 \\
$\quad$ Bachelor's degree & 26 & 12 \\
$\quad$ Graduate degree & & 17 \\
Ethnicity & 6 & 83 \\
$\quad$ Hispanic & 94 & 26 \\
$\quad$ Not Hispanic & & 74 \\
Race & 14 & \\
People of color & 86 & \\
White & &
\end{tabular}

Table 3. By residence, intent to participate in hunting and birdwatching over the next 12 months (expressed as percentages). $\mathrm{U}=$ urban, $\mathrm{M}=$ medium, $\mathrm{R}=$ rural. The first letter represents where respondents grew up, whereas the second letter represents where they live now. Arrows represent moving to a smaller (down arrow) or larger (up arrow) area.

\begin{tabular}{|c|c|c|c|c|c|c|}
\hline Activity & U-U & M-M & $\mathrm{R}-\mathrm{R}$ & $U-\downarrow$ & $R-\uparrow$ & $M-U$ \\
\hline \multicolumn{7}{|l|}{ Hunting $^{\mathrm{a}}$} \\
\hline Not at all likely & $85^{*}$ & 72 & $50^{*}$ & 77 & 70 & 78 \\
\hline Somewhat likely & 8 & 9 & 10 & 10 & 7 & 8 \\
\hline Very likely & $7^{*}$ & 20 & $40^{*}$ & 13 & $23^{*}$ & 14 \\
\hline \multicolumn{7}{|l|}{ Birdwatching ${ }^{b}$} \\
\hline Not at all likely & $34^{*}$ & 30 & 29 & 30 & 28 & $22^{*}$ \\
\hline Somewhat likely & 21 & 24 & 14 & $12^{*}$ & 27 & 23 \\
\hline Very likely & 45 & 46 & 57 & $58^{*}$ & 46 & 56 \\
\hline
\end{tabular}

${ }^{\mathrm{a}} n=902, \mathrm{x}^{2}=60.99, \mathrm{df}=10, p<.01$, Cramer's $\mathrm{V}=.18$

${ }^{\mathrm{b}} n=911, \mathrm{X}^{2}=19.08, \mathrm{df}=10, p=.04$, Cramer's $\mathrm{V}=.10$

* Represents adjusted standardized residuals $>1.96$

least positive attitudes, norms, and PBC. Similar to hunting intent, those who grew up and currently resided in different sized communities had attitudes, norms, and $\mathrm{PBC}$ closest to the $\mathrm{M}-\mathrm{M}$ respondents. People who grew up and currently resided in different sized communities had attitudes, norms, and PBC somewhere in-between those who were U-U or R-R, which suggests that both current and childhood residence are related to hunting. However, the effect sizes for all differences were relatively small (Cohen, 1988).

In contrast, there were no significant differences for birdwatching attitudes, norms, or PBC among the six groups (Figure 2). Overall, respondents expressed more agreeable attitudes toward birdwatching than hunting. Sixty-six percent of the sample reported birdwatching would be pleasant and $60 \%$ reported it would be interesting, compared to 
a)
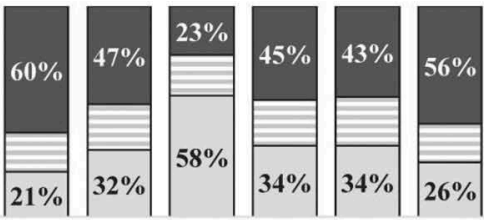

U-U M-M R-R U $\quad$ - $\downarrow \quad R-\uparrow \quad M-U$

$\square$ Pleasant $\square$ Neither $\square$ Unpleasant

c) People important to me would support my hunting
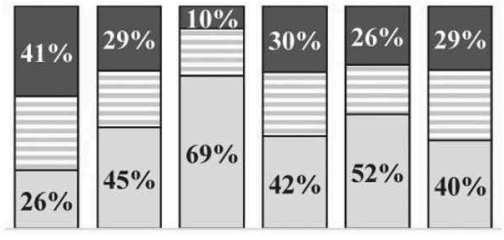

U-U $\quad M-M \quad R-R \quad U-\downarrow \quad R-\uparrow \quad M-U$

$\square$ Agree $\square$ Neither $\square$ Disagree b) Hunting attitudes: interesting vs. boring
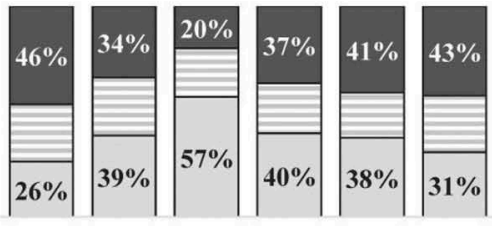

U-U M-M R-R U- $\quad$ R R- $\uparrow \quad M-U$

$\square$ Interesting $\boxminus$ Neither $\square$ Boring

d)

If I wanted to, I could easily go hunting
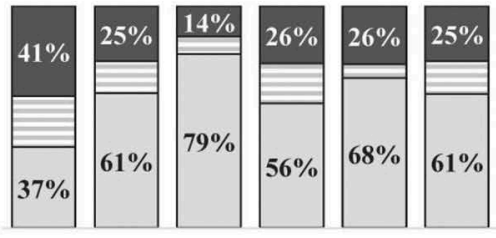

U-U $\quad M-M \quad R-R \quad U-\downarrow \quad R-\uparrow \quad M-U$

$\square$ Agree $\square$ Neither $\square$ Disagree
a) $\chi^{2}=49.46 ; \mathrm{df}=10 ; \mathrm{p}$-value $<.01 ;$ Cramer's $\mathrm{V}=.17$
b) $\chi^{2}=30.99 ; \mathrm{df}=10 ; \mathrm{p}$-value $<.01$; Cramer's $\mathrm{V}=.13$
c) $\chi^{2}=62.82 ; \mathrm{df}=10 ; \mathrm{p}$-value $<.01 ;$ Cramer's $\mathrm{V}=.18$
d) $\chi^{2}=73.07 ; \mathrm{df}=10 ; \mathrm{p}$-value $<.01 ;$ Cramer's $\mathrm{V}=.20$

Figure 1. Hunting attitudes, norms, and perceived behavioral control responses based on place of residency.

$32 \%$ of the sample reporting hunting would be pleasant and $36 \%$ saying it would be interesting. Two-thirds of the sample (68\%) thought that people important to them would support them birdwatching, compared to $42 \%$ who thought that people would support them hunting. Finally, $77 \%$ of the sample believed that they could easily go birdwatching if they wanted, whereas $55 \%$ of the sample reported ease of hunting participation.

\section{Predicting Hunting and Birdwatching Intention}

Adding current or childhood residence did not result in a much better model (Table 4). This was true for both the model examining hunting intention and the model examining birdwatching intention. However, attitudes, norms, and PBC had stronger relation to hunting intention than to birdwatching intention. Although the pseudo $\mathrm{R}^{2}$ statistics showed slight increases in the variance explained when adding current and childhood residence as predictors, the increases were not high enough to warrant these better models (when comparing the $-2 \log$ likelihoods). Given that model 1 had an almost identical fit to the other models, we therefore present results from model 1. 


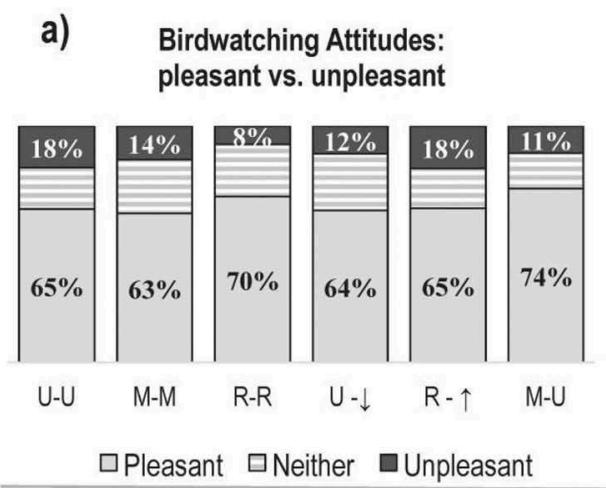

c) People important to me would support my birdwatching

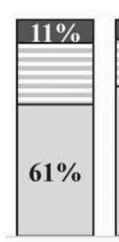

U-U

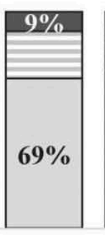

M-M

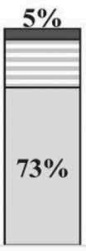

$R-R$

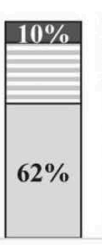

$u-\downarrow$

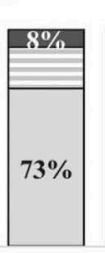

$R-\uparrow \quad M-U$ b)

Birdwatching Attitudes: interesting vs. boring
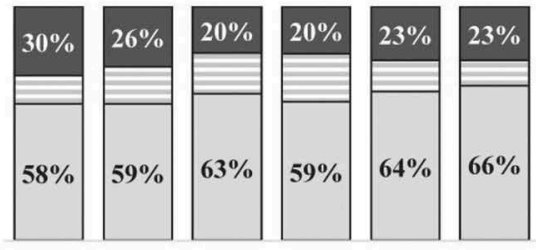

$\begin{array}{llllll}U-U & M-M & R-R & U-\downarrow & R-\uparrow & M-U\end{array}$

\section{$\square$ Agree $\square$ Neither $\square$ Disagree}

d)

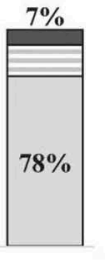

$\square$ Interesting $\boxminus$ Neither $\square$ Boring

If I wanted to, I could easily go birdwatching

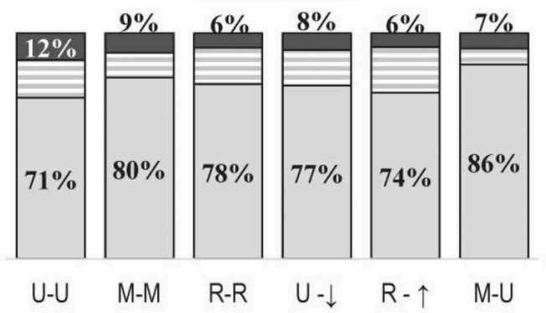

$\square$ Agree $\boxminus$ Neither $\square$ Disagree
a) $\chi^{2}=12.65 ; \mathrm{df}=10 ; \mathrm{p}$-value $=.24$
b) $\chi^{2}=11.32 ; \mathrm{df}=10 ; \mathrm{p}$-value $=.33$
c) $\chi^{2}=18.07 ; \mathrm{df}=10 ; \mathrm{p}$-value $=.05$
d) $\chi^{2}=18.29 ; \mathrm{df}=10 ; \mathrm{p}$-value $=.05$

Figure 2. Birdwatching attitudes, norms, and perceived behavioral control responses based on place of residency.

Table 4. Fit statistics for the four ordinal logistic regression models predicting hunting and birdwatching intention within the next 12 months by TPB factors and current and childhood residencies.

\begin{tabular}{|c|c|c|c|c|c|c|c|c|}
\hline \multirow[b]{3}{*}{ Model: } & \multicolumn{4}{|c|}{ Hunting } & \multicolumn{4}{|c|}{ Birdwatching } \\
\hline & 1 & 2 & 3 & 4 & 1 & 2 & 3 & 4 \\
\hline & TPB & $\begin{array}{l}\text { TPB + } \\
\text { current }\end{array}$ & $\begin{array}{c}\text { TPB + } \\
\text { childhood }\end{array}$ & $\begin{array}{l}\text { TPB }+ \\
\text { both }\end{array}$ & TPB & $\begin{array}{l}\text { TPB + } \\
\text { current }\end{array}$ & $\begin{array}{c}\text { TPB + } \\
\text { childhood }\end{array}$ & $\begin{array}{l}\text { TPB + } \\
\text { both }\end{array}$ \\
\hline $\begin{array}{l}-2 \text { Log } \\
\quad \text { Likelihood }\end{array}$ & 302.75 & 486.06 & 477.58 & 571.71 & 483.15 & 853.89 & 841.42 & 1127.73 \\
\hline Cox and Snell's R ${ }^{2}$ & .49 & .49 & .50 & .50 & .39 & .39 & .39 & .39 \\
\hline Nagelkerke's $\mathrm{R}^{2}$ & .64 & .65 & .65 & .65 & .44 & .44 & .45 & .45 \\
\hline McFadden's $\mathrm{R}^{2}$ & .46 & .47 & .47 & .48 & .24 & .24 & .24 & .24 \\
\hline $\begin{array}{l}\text { Pearson Chi } \\
\text { Square }\end{array}$ & 959.88 & 2095.41 & 1738.39 & 2361.81 & 300.55 & 658.96 & 684.68 & 1087.71 \\
\hline df & 285 & 722 & 740 & 1163 & 223 & 552 & 572 & 991 \\
\hline Significance & $<.01$ & $<.01$ & $<.01$ & $<.01$ & $<.01$ & .01 & .01 & .02 \\
\hline
\end{tabular}

$n=912-942$ for hunting; $n=931-963$ for birdwatching

Pearson Chi Square is testing the overall model; the null hypothesis is that all model coefficients are 0 . 
Table 5. Results from model 1: ordinal logistic regression predicting hunting and birdwatching intention.

\begin{tabular}{lcccccccc}
\hline & Estimate & SE & Wald & df & sig & Odds ratio & $2.5 \%$ OR & $97.5 \%$ OR \\
\hline Hunting intention $(n=942)$ & & & & & & & & \\
Attitudes & 1.53 & 0.12 & 152.72 & 1 & $<.01$ & 4.61 & 3.60 & 5.91 \\
Norms & 0.46 & 0.14 & 11.65 & 1 & $<.01$ & 1.59 & 1.21 & 2.09 \\
PBC & 0.41 & 0.13 & 10.64 & 1 & $<.01$ & 1.51 & 1.17 & 1.94 \\
Birdwatching intention $(n=965)$ & & & & & & & \\
Attitudes & 0.97 & 0.07 & 173.56 & 1 & $<.01$ & 2.65 & 2.28 & 3.07 \\
Norms & 0.08 & 0.09 & 0.64 & 1 & .42 & 1.08 & 0.89 & 1.30 \\
PBC & 0.46 & 0.09 & 26.13 & 1 & $<.01$ & 1.58 & 1.32 & 1.89 \\
\hline
\end{tabular}

Intention is predicted on a 3-point scale: Not at all likely (0), somewhat likely (1), and very likely (2)

The logistic regression statistics showed that attitudes were the strongest predictor of intent to hunt, followed by norms, and then PBC (Table 5). All three predictors were significant $(p<.05)$ and had odds ratios above 1.0. As attitudes, norms, and PBC toward hunting became more positive, people were more likely to intend to hunt. For birdwatching, attitudes were again the strongest predictor of intention, followed by PBC, but norms were not significant. Both attitudes and $\mathrm{PBC}$ had odds ratios above 1.0; as attitudes and $\mathrm{PBC}$ became more positive, people were more likely to intend to birdwatch.

\section{Discussion}

Among U.S. citizens in our sample, we found that the bivariate effect of the urban-rural residence gradient on intent to participate was pronounced for hunting, but not as strong for birdwatching. Although urbanites expressed more negative attitudes toward hunting than did people in rural areas, there was no difference in attitudes toward birdwatching. Further, childhood and current residence did not significantly impact norms or PBC toward birdwatching. These results support previous research that suggests the urban-rural gradient plays a situational role in determining intention to participate in outdoor recreation, when not superseded by stronger effects such as familial ties to an activity (Larson et al., 2014).

The results also suggested that different engagement strategies for birdwatching and hunting may be needed to increase participation in the respective types of outdoor recreation. Regardless of current or childhood position within the urban-rural residence gradient, most respondents suggested they could easily go birdwatching if they wanted and their behavior would be supported by people important to them. Therefore, highlighting birdwatching opportunities near where people live, particularly in urban areas, may be an effective way to encourage more people to go outside and connect to nature (McFarlane \& Boxall, 1996). However, there are still many people who have positive attitudes toward birdwatching and high $\mathrm{PBC}$, yet do not participate. Motivations to participate are often tied to bird-related variables (i.e., seeing birds, seeing different types of birds), especially among those who are already highly involved in the activity (Hvenegaard, 2002). For those less involved, connecting to nature is often more important than bird related variables (Hvenegaard, 2002; Moore, Scott, \& Moore, 2008). Future research is needed to further explore motivations for birdwatching and describe how best to engage potential participants.

Urbanites viewed hunting less favorably, as many respondents who were raised and currently live in urban areas viewed hunting as unpleasant and boring, believed others 
would not support their participation, and believed they could not easily go hunting. Promoting hunting opportunities to individuals with negative attitudes toward this activity is unlikely to increase participation, and these individuals comprised the majority of our sample. That said, previous research has suggested that objections toward hunting may be lowered through frames such as marketing locally-sourced food (i.e., locavore movement) (Stedman, Larson, Tidball, Tidball, \& Curtis, 2017). Hunter engagement efforts for current urban residents or those raised in urban areas may require different approaches than those used for rural-associated individuals (Stedman \& Heberlein, 2001). Future research aimed at contextualizing attitudes that limit participation and other perceived behavioral constraints toward hunting could help to develop recruitment, retention, and reactivation $\left(\mathrm{R}^{3}\right)$ programming that effectively targets people across the urban-rural residence gradient.

The proportion of the sample who reported changing community size categories was notable because this groups' attitudes, norms, PBC, and behavioral intent for hunting tended to be moderate relative to those in the strictly urban or rural groups. This finding suggests both childhood and current community residence may be related to hunting attitudes, norms, $\mathrm{PBC}$, and intentions to participate. Those raised and currently living in a rural area had the strongest intention to hunt, followed by those raised in a rural area who had moved to a larger community. If someone moved from a rural to an urban area, they still may know people who hunt and are influenced by those subjective norms, as people are more likely to participate in an activity if they know others who participate (Schulz, Millspaugh, Zekor, \& Washburn, 2003). People who were raised in rural settings, but moved to larger communities also had the second highest norms and PBC toward hunting, after those raised and currently living in rural areas.

Position along the urban-rural residence gradient is indicative of the role that socialization plays in continued participation in any outdoor recreational activity, but is seemingly important for participating in hunting. Past research efforts have also shown that both childhood and adult socialization plays a role in birdwatching and hunting participation (McFarlane, 1996; O’Leary et al., 1987; Stedman \& Heberlein, 2001). Given that hunting participation rates are higher in rural areas, even if individuals are not directly socialized into hunting through familial connections, they are more likely to maintain other forms of social connections that may lead to socialization (Stedman \& Heberlein, 2001). Future research should seek to understand these processes of socialization and quantify the mechanisms that underlie the urban-rural residence gradient. Applying quantitative methods such as structured equation models in combination with applicable theories that represent social connectedness and network ties (e.g., social network theory and strength of social ties) would elucidate how positive or negative attitudes and behavioral intentions arise in potential participants in wildlife-based recreation.

Hunting and birdwatching are ways to engage people with wildlife outdoors. Getting people outside has the ability to improve mental and physical health, as well as decrease stress and improve attention spans (Bratman, Hamilton, \& Daily, 2012; Mayer et al., 2009; Pretty, 2004). However, these studies examined time spent outdoors in general and did not focus on specific wildlife-related activities. In our study, more respondents reported an intention to birdwatch within the next year than an intention to hunt. Attitudes, norms, and $\mathrm{PBC}$ were also more positive for birdwatching than hunting across all categories of community size. Thus, it may be easier to engage more people in birdwatching rather than hunting. Future research could investigate how wildlife-specific recreation, such as 
birdwatching and hunting, relates to mental and physical health outcomes compared to other types of outdoor recreation.

Increasing outdoor activity participation also has the potential to increase the number of conservationists by increasing connections to nature, thus incentivizing pro-conservation behavior (Cooper et al., 2015; Larson, Cooper, Stedman, Decker, \& Gagnon, 2018; Larson et al., 2015). Urbanites with childhood experiences in nature are more likely to have positive environmental attitudes as adults (Wells \& Lekies, 2006). Similarly, both hunters and birdwatchers have been shown to have higher rates of pro-environmental behavior and conservation behavior compared to non-recreationists (Cooper et al., 2015). Conservation efforts would benefit from expanding engagement efforts to include birdwatchers, particularly since this population is larger, and our results indicate that it may be easier to recruit new birdwatchers than new hunters, particularly in urban areas. That said, future research is necessary to understand how best to engage these birdwatchers in supporting conservation initiatives (Shipley et al., 2019).

Standard TPB variables (i.e., attitudes, subjective norms, $\mathrm{PBC}$ ) have proven to be related to behavior and intention to participate in outdoor recreation activities (Hrubes et al., 2001; Rossi \& Armstrong, 1999; Shrestha et al., 2012). The predictive power of the hunting models in our study (Nagelkerke's $\mathrm{R}^{2}=.64-.65$ ) falls well within the range of variance explained in intent to participate in hunting found in other studies (i.e., 38-93\%) (Hrubes et al., 2001; Rossi \& Armstrong, 1999; Shrestha et al., 2012). However, direct comparisons should be carefully considered when comparing results from an ordinal logistic regression approach, rather than from standard linear regression. In comparing our results for birdwatchers to those for hunters, we saw that TPB concepts explained less variation in the data for birdwatching (Nagelkerke's $\mathrm{R}^{2}=.44-.45$ ) than it did for hunting in our study and among most other applications of the TPB to hunting. This suggests there may be other important variables that are associated with birdwatching intention. Additionally, subjective norms did not significantly impact model predictions for birdwatching, suggesting that people in our sample were not impacted by socially normative pressures associated with this activity. Future research should seek to determine how and why the predictive power of TPB concepts would vary among outdoor recreation activities, especially when drawing comparisons between consumptive and non-consumptive activities such as hunting and birdwatching.

Our modeling exercise showed that directly accounting for current or childhood residence along the urban-rural gradient did not greatly improve the model fit. This is likely due to the interrelatedness of attitudes toward wildlife, nature, conservation, and the urban-rural gradient (Larson et al., 2018; Manfredo et al., 2017). These findings are consistent with previous assumptions that socio-demographic characteristics are likely accounted for indirectly through the standard aspects of TPB (Fishbein \& Ajzen, 2010). Further, our findings are supported by past research that found childhood residence is an important predictor for hunting participation, but only in instances where stronger influences are not present (i.e., males without relatives who hunt) (Stedman \& Heberlein, 2001). Given these findings, we believe that applying and testing the appropriate variables from popular theories such as social network theory or social capital may more directly represent socio-demographics within TPB than background variables such as childhood and current community size (Harshaw \& Tindall, 2005; Uhlik, 2011). 


\section{Limitations}

Our sample did not adequately represent the expected sampling frame. The results were valid, as we compared groups within our sample, but some results (e.g., percentages who hunt and birdwatch) should not be extrapolated to the entire U.S. population. Respondents were more nature and wildlife-oriented compared to the general U.S. population. The sample had a higher proportion of hunters and birdwatchers than other surveys have found in the U.S. (e.g., U.S. Fish and Wildlife Service \& U.S. Census Bureau, 2018), so a more representative sample would likely exhibit attitudes, norms, and PBC indicative of lower interest in participating in both activities. Further, a higher proportion of respondents were male and older than expected, and the sample was less racially diverse than the U.S. population. Given the higher participation rates among white men in both hunting and birdwatching, we likely found more positive attitudes toward these activities than would be expected among the entire U.S. public (U.S. Fish and Wildlife Service \& U.S. Census Bureau, 2018).

Additionally, the small sizes of some of the groups, particularly those who were raised in rural areas, make the margin of error larger for these segments. Due to length constraints of the survey, we were only able to ask one question each to measure PBC and norms, which could influence accuracy. Furthermore, all of our analyses were investigating intent to participate in the next 12 months rather than actual behavior.

\section{Conclusions}

Our study provides insights into how childhood and current community size (urban-rural) may be related to attitudes, norms, $\mathrm{PBC}$, and intention to participate in hunting and birdwatching. Although current and childhood community size were related to attitudes, norms, $\mathrm{PBC}$, and intentions to participate for hunting, community size was not as important for birdwatching. Attitudes toward hunting tended to be more positive for rural residents, and were more negative for urban residents. Attitudes, norms, and PBC associated with birdwatching were less related to the urban-rural gradient compared to hunting, indicating that birdwatching may be a good way to involve more people, particularly urbanites, in wildliferelated recreation. Enhanced understanding of the socio-demographic indicators of wildlife recreation intent, such as the urban-rural gradient, would facilitate more directed and informed actions to increase participation.

\section{Acknowledgments}

The authors are grateful to the North American Waterfowl Management Plan Human Dimensions Working Group and Public Engagement Team for their valuable feedback on the survey instrument. This research was funded by the U.S. Geological Survey, Ecosystems Mission Area, Wildlife Program.

\section{Funding}

This work was supported by the U.S. Geological Survey, Ecosystems Mission Area, Wildlife Program. 


\section{ORCID}

Emily J. Wilkins (1) http://orcid.org/0000-0003-3055-4808

Nicholas W. Cole (10) http://orcid.org/0000-0003-1204-971X

Ashley A. Dayer (iD http://orcid.org/0000-0002-8105-0776

Howard. W. Harshaw (10) http://orcid.org/0000-0001-9568-772X

Andrew H. Raedeke (1) http://orcid.org/0000-0003-3216-6868

\section{References}

Ajzen, I. (1991). The theory of planned behavior. Organizational Behavior and Human Decision Processes, 50(2), 179-211. doi:10.1016/0749-5978(91)90020-T

Ajzen, I., \& Driver, B. L. (1991). Prediction of leisure participation from behavioral, normative, and control beliefs: An application of the theory of planned behavior. Leisure Sciences, 13, 185-204. doi:10.1080/01490409109513137

Berenguer, J., Corraliza, J. A., \& Martín, R. (2005). Rural-urban differences in environmental concern, attitudes, and actions. European Journal of Psychological Assessment, 21(2), 128-138. doi:10.1027/1015-5759.21.2.128

Bratman, G. N., Hamilton, J. P., \& Daily, G. C. (2012). The impacts of nature experience on human cognitive function and mental health. Annals of the New York Academy of Sciences, 1249(1), 118-136. doi:10.1111/j.1749-6632.2011.06400.x

Cohen, J. (1988). Statistical power analysis for the behavioral sciences (2nd ed.). Hillsdale, NJ: Erlbaum.

Coleman, M., Ganong, L. H., Clark, J. M., \& Madsen, R. (1989). Parenting perceptions in rural and urban families: Is there a difference? Journal of Marriage and Family, 51(2), 329-335. doi: $10.2307 / 352496$

Cooper, C., Larson, L., Dayer, A., Stedman, R., \& Decker, D. (2015). Are wildlife recreationists conservationists? Linking hunting, birdwatching, and pro-environmental behavior. The Journal of Wildlife Management, 79(3), 446-457. doi:10.1002/jwmg.855

Cordell, H. K. (2012). Outdoor recreation trends and futures. Asheville, NC. Retrieved from https:// www.srs.fs.usda.gov/pubs/40453

Daigle, J. J., Hrubes, D., \& Ajzen, I. (2002). A comparative study of beliefs, attitudes, and values among hunters, wildlife viewers, and other outdoor recreationists. Human Dimensions of Wildlife, 7(1), 1-19. doi:10.1080/108712002753574756

Dillman, D. A., Smyth, J. D., \& Christian, L. M. (2014). Internet, phone, mail, and mixed-mode surveys: The tailored design method (Vol. 4). Hoboken, NJ: Wiley.

Fishbein, M., \& Ajzen, I. (2010). Predicting and changing behavior: The reasoned action approach. New York, NY: Psychology Press.

Glowinski, S. L., \& Moore, F. R. (2014). The role of recreational motivation in the birding participation-environmental concern relationship. Human Dimensions of Wildife, 19(3), 219-233. doi:10.1080/10871209.2014.878966

Harshaw, H. W., \& Tindall, D. B. (2005). Social structure, identities, and values: A network approach to understanding people's relationships to forests. Journal of Leisure Research, 37(4), 426-449. doi:10.1080/00222216.2005.11950061

Heberlein, T. A. (2008). Hunter declines in North America and Europe: Causes, concerns and proposed research. Pathways to Success Conference, Estes Park, CO. Available from: http://dces. wisc.edu/people/emeritus-faculty/thomas-heberlein/

Heberlein, T. A., \& Ericsson, G. (2005). Ties to the countryside: Accounting for urbanites attitudes toward hunting, wolves, and wildlife. Human Dimensions Of Wildlife, 10(3), 213-227. doi:10.1080/10871200591003454

Howell, E., \& McFeeters, J. (2008). Children's mental health care: Differences by race/ethnicity in urban/ rural areas. Journal of Health Care for the Poor and Underserved, 19(1), 237-247. doi:10.1353/ hpu.2008.0008 
Hrubes, D., Ajzen, I., \& Daigle, J. (2001). Predicting hunting intentions and behavior: An application of the theory of planned behavior. Leisure Sciences, 23(3), 165-178. doi:10.1080/014904001316896855

Huddart-Kennedy, E., Beckley, T. M., McFarlane, B. L., \& Nadeau, S. (2009). Rural-urban differences in environmental concern in Canada. Rural Sociology, 74(3), 309-329. doi:10.1526/003601109789037268

Hvenegaard, G. T. (2002). Birder specialization differences in conservation involvement, demographics, and motivations. Human Dimensions of Wildlife, 7(1), 21-36. doi:10.1080/108712002753574765

Jones, R. E., Fly, J. M., \& Cordell, H. K. (1999). How green is my valley? Tracking rural and urban environmentalism in the southern Appalachian ecoregion. Rural Sociology, 64(3), 482-499. doi:10.1111/j.1549-0831.1999.tb00363.x

Jones, R. E., Fly, J. M., Talley, J., \& Cordell, H. K. (2003). Green migration into rural America: The new frontier of environmentalism? Society and Natural Resources, 16(3), 221-238. doi:10.1080/ 08941920390178793

Kollmuss, A., \& Agyeman, J. (2002). Mind the gap: Why do people act environmentally and what are the barriers to pro-environmental behavior? Environmental Education Research, 8(3), 239-260. doi:10.1080/13504620220145401

La Rouche, G. P. (2003). Birding in the United States: A demographic and economic analysis. Addendum to the 2001 national survey of fishing, hunting, and wildlife-associated recreation. Washington, DC: U. S. Fish and Wildlife Service.

Larson, L. R., Cooper, C. B., Stedman, R. C., Decker, D. J., \& Gagnon, R. J. (2018). Place-based pathways to proenvironmental behavior: Empirical evidence for a conservation-recreation model. Society \& Natural Resources, 31(8), 871-891. doi:10.1080/08941920.2018.1447714

Larson, L. R., Stedman, R. C., Cooper, C. B., \& Decker, D. J. (2015). Understanding the multi-dimensional structure of pro-environmental behavior. Journal of Environmental Psychology, 43, 112-124. doi:10.1016/j.jenvp.2015.06.004

Larson, L. R., Stedman, R. C., Decker, D. J., Siemer, W. F., \& Baumer, M. S. (2014). Exploring the social habitat for hunting: Toward a comprehensive framework for understanding hunter recruitment and retention. Human Dimensions of Wildlife, 19(2), 105-122. doi:10.1080/10871209.2014.850126

Lessard, S. (2017). The human dimensions of whooping crane conservation in Alabama (Unpublished master's thesis). Auburn University.

Lichter, D. T., \& Brown, D. L. (2011). Rural America in an urban society: Changing spatial and social boundaries. Annual Review of Sociology, 37, 565-592. doi:10.1146/annurev-soc-081309-150208

Lovelock, B., Walters, T., Jellum, C., \& Thompson-Carr, A. (2016). The participation of children, adolescents, and young adults in nature-based recreation. Leisure Sciences, 38(5), 441-460. doi:10.1080/01490400.2016.1151388

Lowe, G. D., \& Pinhey, T. K. (1982). Rural-urban differences in support for environmental protection. Rural Sociology, 47(1), 114-128.

Manfredo, M. J., Bruskotter, J. T., Teel, T. L., Fulton, D., Schwartz, S. H., Arlinghaus, R., ... Kitayama, S. (2017). Why social values cannot be changed for the sake of conservation. Conservation Biology, 31(4), 772-780. doi:10.1111/cobi.12855

Manfredo, M. J., Teel, T. L., \& Henry, K. L. (2009). Linking society and environment: a multilevel model of shifting wildlife value orientations in the western united states. Social Science Quarterly, 90(2), 407-427. doi:10.1111/ssqu.2009.90.issue-2

Mayer, S. F., Frantz, C. M., Bruehlman-Senecal, E., \& Dolliver, K. (2009). Why is nature beneficial? The role of connectedness to nature. Environment and Behavior, 41(5), 607-643. doi:10.1177/ 0013916508319745

McFarlane, B. L. (1996). Socialization influences of specialization among birdwatchers. Human Dimensions of Wildlife, 1(1), 35-50. doi:10.1080/10871209609359050

McFarlane, B. L., \& Boxall, P. C. (1996). Participation in wildlife conservation by birdwatchers. Human Dimensions of Wildlife, 1(3), 1-14. doi:10.1080/10871209609359066

Miller, Z. D. (2017). The enduring use of the theory of planned behavior. Human Dimensions of Wildlife, 22(6), 583-590. doi:10.1080/10871209.2017.1347967

Moore, R. L., Scott, D., \& Moore, A. (2008). Gender-based differences in birdwatchers' participation and commitment. Human Dimensions of Wildlife, 13(2), 89-101. doi:10.1080/10871200701882525 
O’Leary, J. T., Behrens-Tepper, J., Mcguire, F. A., \& Vio, F. D. D. (1987). Age of first hunting experience: Results from a nationwide recreation survey. Leisure Sciences, 9(4), 225-233. doi:10.1080/01490408709512164

Pretty, J. (2004). How nature contributes to mental and physical health. Spirituality and Health International, 5(2), 68-78. doi:10.1002/(ISSN)1557-0665

Quartuch, M. R., Stedman, R. C., Decker, D. J., Larson, L. R., Siemer, W. F., \& Baumer, M. S. (2017). Exploring nontraditional pathways into hunting in New York State: Implications for recruitment and retention. Human Dimensions of Wildlife, 22(5), 391-405. doi:10.1080/10871209.2017.1334247

Reiter, D. K., Brunson, M. W., \& Schmidt, R. H. (1999). Public attitudes toward wildlife damage management and policy. Wildlife Society Bulletin, 27(3), 746-758.

Robison, K. K., \& Ridenour, D. (2012). Whither the love of hunting? Explaining the decline of a major form of rural recreation as a consequence of the rise of virtual entertainment and urbanism. Human Dimensions of Wildlife, 17(6), 418-436. doi:10.1080/10871209.2012.680174

Rossi, A. N., \& Armstrong, J. B. (1999). Theory of reasoned action vs. theory of planned behavior: Testing the suitability and sufficiency of a popular behavior model using hunting intentions. Human Dimensions of Wildlife, 4(3), 40. doi:10.1080/10871209909359156

Schulz, J. H., Millspaugh, J. J., Zekor, D. T., \& Washburn, B. E. (2003). Enhancing sport-hunting opportunities for urbanites. Wildlife Society Bulletin, 31(2), 565-573.

Shipley, N. J., Larson, L. R., Cooper, C. B., Dale, K., LeBaron, G., \& Takekawa, J. (2019). Do birdwatchers buy the duck stamp? Human Dimensions of Wildlife, 24(1), 61-70. doi:10.1080/ 10871209.2018.1517227

Shrestha, S. K., \& Burns, R. C. (2016). Integrating constraints to the theory of planned behavior in predicting deer hunting participation. Human Dimensions of Wildlife, 21(5), 445-459. doi:10.1080/10871209.2016.1187779

Shrestha, S. K., Burns, R. C., Pierskalla, C. D., \& Selin, S. (2012). Predicting deer hunting intentions using the theory of planned behavior: A survey of Oregon big game hunters. Human Dimensions of Wildlife, 17(2), 129. doi:10.1080/10871209.2012.649885

Stedman, R. C., \& Heberlein, T. A. (2001). Hunting and rural socialization: Contingent effects of the rural setting on hunting participation. Rural Sociology, 66(4), 599-617. doi:10.1111/j.15490831.2001.tb00086.x

Stedman, R. C., Larson, L. R., Tidball, K. G., Tidball, M., \& Curtis, P. D. (2017). Hunting and the local food movement: Insights from central New York State. Wildlife Society Bulletin, 41(4), 720-728. doi:10.1002/wsb.802

Teel, T. L., Krannich, R. S., \& Schmidt, R. H. (2002). Utah stakeholders' attitudes toward selected cougar and black bear management practices. Wildlife Society Bulletin, 30(1), 2-15.

Teel, T. L., \& Manfredo, M. J. (2010). Understanding the diversity of public interests in wildlife conservation. Conservation Biology, 24(1), 128-139. doi:10.1111/j.1523-1739.2009.01374.x

U.S. Census Bureau. (1993). Table 4: Population: 1790 to 1990. Retrieved from https://www.census. gov/population/censusdata/table-4.pdf

U.S. Census Bureau. (2015). 2010 census urban area FAQs. Retrieved from https://www.census.gov/ geo/reference/ua/uafaq.html

U.S. Fish and Wildlife Service \& U.S. Census Bureau. (2014). 2011 National survey of fishing, hunting, and wildlife-associated recreation. Retrieved from https://www.census.gov/prod/ 2012pubs/fhw11-nat.pdf

U.S. Fish and Wildlife Service \& U.S. Census Bureau. (2018). 2016 National survey of fishing, hunting, and wildlife-associated recreation. Retrieved from https://wsfrprograms.fws.gov/sub pages/nationalsurvey/nat_survey2016.pdf

Uhlik, K. (2011). Revisiting the strength of weak ties: Lessons learned from social network leisure research. Leisure/Loisir, 35(4), 453-470. doi:10.1080/14927713.2011.650855

Walker, A. J., \& Ryan, R. L. (2008). Place attachment and landscape preservation in rural New England: A Maine case study. Landscape and Urban Planning, 86(2), 141-152. doi:10.1016/j. landurbplan.2008.02.001 
Weber, B., Jensen, L., Miller, K., Mosley, J., \& Fisher, M. (2005). A critical review of rural poverty literature: Is there truly a rural effect? International Regional Science Review, 28(4), 381-414. doi: $10.1177 / 0160017605278996$

Wells, N. M., \& Lekies, K. S. (2006). Nature and the life course: Pathways from childhood nature experiences to adult environmentalism. Children Youth and Environments, 16(1), 1-24.

Wilkins, E. J., \& Miller, H. M. (2018). Public views of wetlands and waterfowl conservation in the United States-Results of a survey to inform the 2018 update of the North American waterfowl management plan (2017-1148). Reston, VA. Retrieved from http://pubs.er.usgs.gov/publication/ ofr20171148

Wilkins, E. J., Miller, H. M., \& Schuster, R. (2017). Results of a U.S. General Public Survey to Inform the 2018 North American Waterfowl Management Plan Update. doi:10.5066/F7G15ZQ6

Woods, M. (2009). Rural geography: Blurring boundaries and making connections. Progress in Human Geography, 33(6), 849-858. doi:10.1177/0309132508105001

Zinn, H. C., Manfredo, M. J., \& Barro, S. C. (2002). Patterns of wildlife value orientations in hunters' families. Human Dimensions of Wildlife, 7(3), 147-162. doi:10.1080/10871200260293324 